\title{
MANUEL ROMERO DE TERREROS Y LA ARQUITECTURA RELIGIOSA COLONIAL
}

Por Francisco de la Maza

Es curioso observar que en la extensa e interesante producción historiográfica que escribió Manuel Romero de Terreros sobre la Nueva España, la parte sobre arquitectura religiosa colonial es la más escasa. Su atención se dirigió, más bien, hacia la arquitectura civil, las artes menores y la vida social del Virreinato, como si una secreta nostalgia lo empujara al gusto de describir, historiar y darnos a conocer con mayor amplitud, las casas que, por su abolengo y familia, fueran las que ocuparon sus ascendientes. El, que debla de poseer y habitar el antiguo palacio de su abuelo el conde de Regla, tuvo que sufrir, por los malhadados años de los veintes, la destrucción de su interior para convertirlo en hórridos departamentos dizque modernos. Sólo fue perdonada la fachada, si bien, despojada de su escudo y otros ornamentos que tenía y con un tercer piso abominable.

De sus casi quinientas fichas biblio-hemerográficas, apenas si unas treinta se dedican a la arquitectura religiosa.

Es bien comprensible esta actitud del marqués de San Francisco, por tener a sus espaldas las dos obras entonces fundamentales de la historia del Arte Colonial de México: la de don Manuel Revilla y la de Sylvester Baxter, que se ocupaban preponderantemente de los templos y conventos de nuestro país.

Es hasta 1913 en que, de una manera incidental, habla del templo de San Agustin, al referirse a la Biblioteca Nacional de México. Muchos años después haria un amplio estudio sobre dicho templo.

En 1914 en el periódico Excelsior, el 21 de mayo, publicó un artículo titulado: "Encuestas sobre el ciprés de la catedral", en el que se refiere a las opiniones respecto de la conservación o destrucción del Altar Mayor de nuestra sufrida catedral. Por supuesto que las opiniones destructoras, como casi siempre en México, fueron las que ganaron. En 1967 - jcuánto "ha llovido" la destrucción desde entonces!- volvió a sufrir el Marqués ante el incendio de parte del coro y del retablo del Perdón y las inmediatas e improvisadas opiniones de acabar de destruir lo que el incendio había dejado, opiniones que con más o menos oropel de cientificismo y malévola justificación, se sostienen hoy dfa.

Fue en 1916 cuando comenzó a publicar una de sus obras más bellas 
y consistentes: los tres tomos del Arte colonial, en los cuales se ocupa de arquitectura religiosa en el tomo segundo al hacer un detallado y magnifico estudio sobre el colegio de Tepozotlán y otro sobre Tresguerras. En el primero luce Romero de Terreros sus dotes de fino estilista, de culto historiador y de observador sagaz. Comienza diciendo: "Cerca de Cuautitlán el proverbial; a la falda de los montes que al noroeste limitan el Valle de México; y sobre una colina, árida pero rodeada de sembrados que fecundiza un riachuelo, se levanta la vetusta mole del Seminario de San Martín de Tepozotlán. .." Cuenta la historia del colegio con toda la documentación que tuvo en sus manos y que era entonces exhaustiva. Describe con minucia, amor y conocimientos todo el edificio y se queja del estado de abandono en que por aquellos años se encontraba.

En cuanto al famoso y ahora un tanto debatido arquitecto Francisco Eduardo Tresguerras, estudia su vida y sus obras hasta donde pudo en esa época y si bien está más presto al elogio que a la censura ante el famoso arquitecto de Celaya, tiene mucho cuidado en destruir algunas de las falsas atribuciones que se le hacen, como la construcción de los retablos de Santa Clara y Santa Rosa de Querétaro.

Estudia todas las obras de Tresguerras en Celaya, Querétaro, Guanajuato y San Luis Potosí, pero, nos dejó con la creencia de que el bellísimo palacio del conde de Rul, en Guanajuato, fue obra suya. En realidad no sabemos quién la hizo, pero dudamos vigorosamente que sea de Tresguerras, pues no hubiera dejado de enorgullecerse de él en sus escritos. Niega en cambio, y con toda razón, que Tresguerras construyera la Alhóndiga de Granaditas.

En el tomo tercero vuelve a ocuparse de la arquitectura religiosa en tres capítulos: "La iglesia y monasterio de San Agustín de Acolman", el "Camarín de los Remedios" y (aun cuando no es obra de arquitectura) "La silleria del coro de Guadalupe".

Como en el caso de Tepozotlán la cuidadosa y cariñosa descripción del convento de Acolman, es excelente y si hubo un error al leer una inscripción de los capiteles de las columnas que separan la nave del presbiterio, pues Romero de Terreros leyó "Maestro Palomira Físsome", en una nota al final del artículo rectificó su mala lectura cuando Federico Gómez de Orozco le hace saber que decía. "Maestro Alonso de la Vera† Provincial".

En cuanto al camarín de los Remedios es la única vez que se le ha estudiado. Reproduce la descripción que hiciera de el en el siglo XvII el padre Florencia en la cual dice el barroco y fecundo jesuita: "Acabada la bóveda del camarín se adornó de curiosa lacería de yeso para lo cual 
se trajo de la Puebla, un maestro, eminente en su arte, el cual bruñó todos los lazos, de modo que no parecen de yeso, sino de mármol blanco y muy fino. Adornáronse las paredes con varios cuadros de insigne pintura con marcos de una misma hechura, muy preciosos. El altar que allf se fabricó y los ornamentos de todos colores que sirven al sacrificio de la misa, los candeleros de plata, cálices, vinajeras, salvillas, todo está con tanto primor y abundancia que sólo podrá admirarlo todo quien tuviera la dicha de verlo."

Por supuesto que 250 años después, el marqués de San Francisco tendría que exclamar: "inútil nos parece decir que de todo esto nada queda, con excepción del techo del Camarín, el cual, a pesar de haber sido embadurnado con una espesa capa de pintura, conserva su atractivo de antaño. Consiste en una bóveda con lunetos, cubierta en sus cuatro secciones con lacerfa de hermoso diseño de florones, piñas, racimos de uvas y querubines"; añade que "el maestro de Puebla fue quizás uno de los que hicieran las hermosas lacerías del techo de la capilla del Rosario de aquella ciudad..." Esto último pudiera ser verdad, ya que el libro en el que habla el padre Florencia del camarin de los Remedios, - sea el Zadiaco mariano, lo dejó inédito poco antes de su muerte en 1695, cuando la obra de la capilla del Rosario estaba terminada desde 1690.

Todos estos estudios fueron reproducidos después en diversas revistas, con lo cual les dio mayor difusión. En México la reiteración, en lo que se refiera a conocimientos culturales, no es un defecto, sino una virtud necesaria.

En cuanto a la arquitectura de retablos fue muy parvo nuestro marqués, pues solamente se ocupó del de nuestra Señora de Guadalupe, en el santuario de Ocotlán, en la revista La Rosa del Tepeyac en el año de 1920. En la misma revista y en el mismo año publicó un breve pero enjundioso artículo sobre La Villa de Guadalupe a mediados del siglo $X V I I I$ en que si bien la parte principal de él es el estado en que se encontraba en esa época la citada villa, ocupa lugar preferente la descripción y valoración del santuario. Entonces no se sabla que su arquitecto habia sido el insigne Pedro de Arrieta, por lo cual no está citado, pero que, a buen seguro, hubiera gustado mucho a Romero de Terreros el incluirlo entre los grandes arquitectos del siglo xvin mexicano.

No conozco desafortunadamente un texto en inglés que publicó en las "Monografias Mexicanas de" Arte" número 3 llamado Churches and convents of the city of Mexico, que cita Jose Miguel Quintana en la 
"Bibliohemerografia" de Romero de Terreros, publicada en el Boletín Bibliográfico de la Secretaría de Hacienda y Crédito Público en 1965.

En 1922 publicó una utilísima Historia sintética del arte colonial en México, de la editorial Porrúa, en la cual abarca todos los aspectos de dicho arte y una bibliografía general. En 1951 la misma casa editora hizo una segunda edición o, como se dice en la advertencia, "una nueva versión de nuestra historia sintética del Arte Colonial, agotada desde hace bastantes años y que mereció favorable acogida tanto en México como en el extranjero"; esta segunda edición lleva por título El Arte en México durante el virreinato y es que de 1922 a 1951, Romero de Terreros se convenció de una tesis que sostuvo siempre: de que México ; las otras actuales repúblicas de Hispanoamérica no fueron colonias y prefirió ya referirse siempre a lo "Virreinal". Largas serian las discusiones - como las que sostuve de palabra con el propio marqués sobre si es más legitimo hablar de "Colonial" o "Virreinal" al arte y a la historia de los 300 años de la ocupación española en América.

Indudablemente da más categoría hablar de "Virreinal" y no de "Colonial", pero chasta qué punto es cierto que las posesiones españolas en América no fueran verdaderas colonias, ya sea en el sentido antiguo romano de extensión de las costumbres y los derechos a regiones de diversa cultura que la romana o en el sentido moderno de las colonias de explotación a la manera europea? Creo que la colonización española en América fue ambas cosas y si bien tiene el aspecto materialista de la explotación de las riquezas, también tiene el de la extensión de la cultura que los romanos dieron a la palabra colonia. Nunca la ciudad de Colonia, en Alemania, se ha arrepentido de llamarse asi y conservar el recuerdo de que fue una de las avanzadas del Imperio Romano en la antigua Germania. Por otra parte la palabra "Virreinal" sólo competería a México y al Perú pues, las demás regiones fueron capitanías generales (el virreinato de Buenos Aires fue muy tardio y por eso nos olvidamos de él en este caso) y entonces ¿cómo llamarle al arte de tres siglos de Guatemala, Cuba o el Brasil?

Deciamos que este libro, sobre todo en su segunda edición es un deleitoso y eficaz resumen histórico del arte de la Nueva España. Comienza con una indispensable advertencia sobre los nombres de los estilos que se plasmaron en nuestras artes plásticas de la época colonial. Dice muy bien Romero de Terreros, que, con relación a la arquitectura, la escultura y demás manifestaciones artisticas del virreinato, es un error emplear el término "estilo colonial", puesto que, durante la dominación 
española en Méxica, no solamente se siguió uno, sino diversos estilos (o más bien, caracteres de ornamentación), que fueron sucediéndose y modificándose al correr del tiempo. Lo que es lógico es hablar de "Arte Colonial" con sus diferentes estilos, de los cuales Romero de Terreros recuerda el plateresco, el herreriano, y el "pujante" barroco. En cuanto al estilo del siglo xvin dice que "se transformó en el ultrabarroco o churrigueresco", término este último que acepta "para darle el nombre ya concreto entre nosotros". Añade que si el barroco en México "fue una exigencia, por decirlo ast, del plateresco, el churrigueresco fue una exigencia del barroco". No estamos completamente de acuerdo en esta última aseveración, ya que el barroco -el del siglo xviı- no deriva del plateresco, ni toma ninguna de sus formas, así como el churrigueresco tiene elementos formales suficientes para independizarse del manierismo y del barroco salomónico que le hablan precedido.

Un trabajo amplio y detallado sobre arquitectura religiosa fue el de "La iglesia y convento de San Agustín", publicación del Instituto de Investigaciones Estéticas en el año de 1961, en que la Universidad cambió sus instituciones de los antiguos edificios a la actual Ciudad Universitaria. Se quiso entonces dejar un recuerdo de los edificios que habia ocupado en la Ciudad Vieja y encargó a todos los miembros del Instituto una monografía sobre cada uno de ellos. Es curioso que la única Institución que permaneció en la antigua ciudad de México-que ya no debemos llamar "centro"- fue la Biblioteca Nacional, en la iglesia de San Agustín. En esta monografía Romero de Terreros hizo cumplida historia del edificio y una descripción muy completa. Olvidó, sin embargo, el curioso caso que se suscitó en cuanto a la conservación o destrucción del relieve del San Agustín de la fachada principal, que estuvo a punto de ser raspado por la ignorancia artística y el jacobinismo desaforado del famoso "Nigromante", o sea el muy ilustre en otros aspectos, el liberal Ignacio Ramirez. Muy atinadamente reproduce en los apéndices algunos documentos referentes a este grandioso templo, como el contrato para el retablo mayor, que comenzó en 1697 el escultor Tomás Juárez pero que fue incendiado en 1754 . El que llegó hasta nosotros fue un espléndido retablo salomónico, que conocemos gracias a una nitida litografía de 1856 en la Revista La Cruz.

En 1952 publicó en estos Anales un breve pero sazonado estudio sobre "La iglesia de San Francisco de México", en el cual describe el antiguo templo franciscano de la ciudad y lo ilustra con excelentes litografias y fotografias. 
Fuera de la ciudad de México se ocupó de algunas construcciones religiosas ya sea en revistas o en folletos especializados. Por ejemplo, en las Memorias de la Academia Mexicana de la Historia, de 1953 escribió sobre "El antiguo convento franciscano de Tepeyanco", es decir, sobre la imponente y grandiosa ruina de este monasterio que debería restaurarse para salvarlo de la humillación en que está frente a la petulante parroquia. Otro convento estudiado por él fue el de Atlatlauhcan, publicado por el Instituto Nacional de Antropologia e Historia en 1956. Este monasterio es uno de los más vigorosos que se construyeron en la Nueva España y que aun conservan su Capilla Abierta y sus Capillas Posas todas almenadas, de tal manera que se impone a la vista como un grandioso conjunto medieval. Por desgracia en esa época aún no habia sido abierta la Capilla Abierta, ya que la mayoria de las citadas capillas, llamadas también Capillas de Indios, fueron cegadas durante el siglo pasado -y aún en éste- por la ignorancia de los curas encargados de los templos y así permanecen la mayoria de ellas. Ia monografía está espléndidamente ilustrada con afortunadas fotografías y dibujos del Departamento Fotográfico del Instituto. En la misma serie publicó Romero de Terreros, en 1959, otra excelente monografía sobre el convento de Ayotzingo, dando a conocer no sólo el edificio con su claustro del siglo xvi, y su iglesia del siglo xvir, sino descubriendo unas interesantes pinturas que él atribuyó, con prudentes dudas, a Simón Pereyns.

En ese mismo año y en nuestros Anales publicó otro estudio sobre "El convento franciscano de Ozumba y las pinturas de su porteria" y después, en 1961, otro sobre "El convento dominicano de Chilmahuacán, Chalco", así como en los Anales del Museo de Antropología e Historia, el de "Zoyatzingo."

Desconocida era, en la ciudad de México, por estar envuelta en feísimas construcciones posteriores, la Capilla de las Recogidas o de la Magdalena, pequeña y preciosa obra neoclásica - salvo la horrible linternilla posterior- que existe (ahora descubierta) en el antiguo barrio de San Lucas. Manuel Romero de Terreros la estudió y dio a conocer en el justo "Homenaje a Pablo Martínez del Río", libro publicado por el Instituto Nacional de Antropologia e Historia en 1961 .

Por último, en 1964, escribió sobre "El antiguo monasterio agustino de San Miguel Acatlán", "Las torres de la catedral de Guadalajara" y "La Misión Franciscana de San Sabás" en los números 34 y 35 de estos Anales.

Don Manuel Romero de Terreros fue el puente que unió a otros dos 
historiadores del Arte de México: don Manuel Revilla y don Manuel Toussaint, trinidad imprescindible en to que se refiere, sobre todo, al gran Arte Virreinal -digámoslo así en homenaje al denodado defensor del término- de México. 